\title{
A narrative account of the wider impact of the 7 July 2005 London bomb attacks
}

Shahid Bux

University of St Andrews

Sarah M. Coyne

Brigham Young University - Provo, smcoyne@byu.edu

Follow this and additional works at: https://scholarsarchive.byu.edu/facpub

Part of the Other Social and Behavioral Sciences Commons, and the Terrorism Studies Commons

\section{Original Publication Citation}

Bux, S. M., \& Coyne, S. M. (2009). A narrative account of the wider impact of the 7 July 2005 London bomb attacks. Journal of Aggression, Conflict, and Peace Research, 1, 24-36.

\section{BYU ScholarsArchive Citation}

Bux, Shahid and Coyne, Sarah M., "A narrative account of the wider impact of the 7 July 2005 London bomb attacks" (2009). Faculty Publications. 4030.

https://scholarsarchive.byu.edu/facpub/4030 


\title{
A narrative account of the wider impact of the 7 July 2005 London bomb attacks
}

\author{
Shahid Bux \\ University of St Andrews, Scotland \\ Sarah M Coyne \\ Brigham Young University, USA
}

\begin{abstract}
The London bombings on 7 July 2005 highlighted the prevailing terrorist threat to the UK. The present study addressed the psychological response of a community $(n=294)$ indirectly exposed to the attacks to discern the broader impact and effects of terrorism. Qualitative content analysis was used to develop a profile of emotions and responses to the attacks. This was supplemented by the use of linguistic analysis demonstrating the enormous heterogeneity and complexity of responses to terrorism. In light of previous work on the wider impact of terrorism, the present study highlighted a relatively restrained impact of terrorism. Notwithstanding this observation, responses were marked by negative emotions, with increased use of references to others than for self. Responses also highlighted the use of psychological distancing more among white than Asian respondents, and the importance of religion, both as a supportive factor and perceived cause of the attacks, with references more prevalent among Asian respondents. Although the ubiquitous nature of negative emotions also slightly heightened reports of perceived risk, the ability of respondents to use methods of social orientation helped their ability to recover, and may be crucial in helping harness unified community-based responses to terrorism.
\end{abstract}

\section{KEY WORDS}

Terrorism; emotions; perceived risk; psychological distancing; religion.

The terrorist attacks on London on 7 July 2005 killed 52 people and injured at least 700 . The attacks, the work of suicide bombers, were the first of their kind in British history. Although the destruction was confined to the city of London, the broader effects of terrorism tend to linger among entire nations and communities (Gurwitch et al, 2002). While the number of people killed in a terrorist attack is small in comparison to the number of people who die in civil wars or car accidents (Mueller, 2005), such events tend to resonate in the minds of the viewing public (Healy et al, 2002). They also induce emotions and reactions of an incalculable nature throughout the populace. This article addresses the response and reaction of a community indirectly exposed to the London bombings to assess the broader impact and implications of the attacks.

Since September 112001 (9/11), the interest in terrorism studies has blossomed. In particular, the literature has been dominated by studies examining the effects of terrorism, often focused on the direct victims of terrorist atrocity and their associated emotional responses, coping methods and stress or traumatic symptoms. Relatively less common are studies focused on individuals indirectly exposed to terrorism. Given that one of the primary objectives of terrorism is to induce feelings of fear, uncertainty and vulnerability throughout the populace, this study represents an important step in understanding 
the wider implications of terrorism. Examining the broader response provides some insight into the relative success of a terrorist attack in inducing its targeted objectives, but also allows us to consider the implications of a terrorist attack in terms of emotional responses and behavioural changes. Considering the broader response to terrorism is also highly relevant in efforts to counteract its effects, since fostering community-based responses that reflect a sense of cohesion and resilience are crucial in undermining the effects of terrorism and the goals of terrorists.

One of the more significant studies evaluating the psychological impact of terrorist activity was conducted by Friedland and Merari (1985). The authors presented the results of a public opinion survey, conducted on an Israeli national sample. They found that terrorism was highly effectual in eliciting fear, even when the actual damage it caused may be relatively restrained. They also suggested that terrorism could be described as a form of 'psychological warfare' on the basis of a perception of threat that far exceeds the capabilities of the terrorists and the ability to impinge on individuals beyond those directly affected by the violent act. The random nature of the act creates feelings of fear and vulnerability in a large proportion of individuals who identify with the direct victims of the attack. This 'vicarious' dimension contributes to increased panic and apprehension among the community (Hoffman, 1998).

This was apparent in the immediate response to the London attacks. Retail sales decreased by $8.9 \%$ in the London, the worst reported slump since 2002, while shoppers and day-trippers kept their distance from the city (Press Association, 2005). Tube travel also dropped substantially, by 10-15\% (Smith, 2005). In one of the first studies on the impact of the London attacks Rubin and colleagues (2005) found that many Londoners showed healthy emotional responses, while many others were marked by a change in behaviour and lifestyle. Up to $32 \%$ reported that they would reduce the amount of public transport used to Central London, including buses, tubes and trains, while bike sales increased by $20 \%$ as a result of the attacks. In addition, $55 \%$ of Londoners believed that they were personally at risk, while $58 \%$ believed that family or friends were in danger. In a follow up study seven months later, Rubin and colleagues (2007) found that extensive stress (11\%), perceived threat to self ( $43 \%)$, and a decrease in travel due to the bombings (19\%) continued at a lower intensity, while other perceived threats persisted unchanged.
Importantly, the effects of terrorism are not confined to the immediate locale of the terrorist attack. Studies conducted in the aftermath of the Oklahoma City bombings and 9/11 revealed that symptoms of stress were indeed evident crossnationally (Apolone, Mosconi \& Vecchia, 2002; Galea et al, 2002; Schuster et al, 2001; Somer et al, 2005; Sprang, 1999). Terrorist attacks are also unique as a result of their unpredictable nature. This sense of unpredictability contributes to extending the duration of risk perception. A survey of nursing students nine months after September 11 (Young \& Persell, 2004) found that $55 \%$ thought there was 'little chance of terrorism occurring in the area', while $41 \%$ thought it 'somewhat likely'. Almost two-thirds (64\%) reported no lifestyle change, while $35 \%$ reported changes in travel habits and $39 \%$ identified personal changes, particularly relating to family and religion.

It is clear that responses to terrorism tend to be disparate and diverse among the broader populace. Following the attacks on September 11 2001, a number of people were asked about specific emotions. Anger and sadness (Saad, 2001b) were most frequently mentioned among feelings of fear and anxiety. Up to $63 \%$ reported a reduced sense of personal safety (Saad, 2001b), while $54 \%$ worried that a family member would become the victim of a terrorist attack (Gallup News Service, 2001). In a more in-depth study of responses to terrorism, Cohn et al (2004) analysed the online diaries of US citizens before and after 9/11. They used a textual analysis programme to assess various psychological aspects such as emotionality, cognitive distancing, and social awareness. After the attacks, participants showed more negative emotions, more social awareness, and more distancing strategies, although the effects were relatively short-lived. These effects were not moderated by demographic factors such as location, gender, or age.

However, many people also felt grateful to be alive and took comfort in the knowledge that loved ones were safe. Also evident were greater feelings of love as a result of an uncertain future (Fredrickson, 1995; Fredrickson \& Carstensen, 1990; Saad, 2001a). Positive emotions including optimism, love and trust helped provide pleasant subjective experiences, while generally serving to reduce panic and apprehension. Another study revealed that $90 \%$ of a national sample turned to prayer, religion or spiritual feelings (Schuster et al, 2001). Religious and faith communities help to enhance feelings 
of comfort, control and connectedness, which can be used as positive coping strategies, providing a number of benefits including lower perceptions of vulnerability, isolation, confusion and symptoms of stress (Meisenhelder, 2002).

It is noticeable from the literature reviewed that terrorism can have a large psychological impact on an individual's emotional and attitudinal response, even when that individual is not a direct victim of the attacks. Through narrative accounts, the present study attempts to provide some understanding of the impact of terrorism on communities not directly affected by the 7 July 2005 London attacks. Given the high media profile of terrorism, the psychological literature on the impact of terrorism is not particularly rich (Silke, 2003). In particular, we know surprisingly little about the psychological effects of terrorism on people distant from the sites of terrorist attacks. Are people in the broader population traumatised or do people exhibit a greater sense of resilience? How do people's emotional responses impact on their level of perceived risk? These are some of the questions that the present study helps to shed light on. The London attacks on 7 July 2005 were among the worst terrorist atrocities on mainland Britain, and represented a new development in the use of terrorist tactics in Britain. This study is one of the first in the UK on people indirectly exposed to the London attacks, and one of few qualitative studies to examine the impact of terrorism. The qualitative nature of the study provides rich and insightful detail into emotions and attitudes that reflect the broader impact of terrorism, allowing an appreciation of the complex and heterogeneous nature of responses to terrorism. This study also adds to the literature on the wider impact of terrorism, demonstrating the psychological cost terrorism inflicts on wider societies.

\section{Method \\ Participants}

Participants consisted of 294 individuals $(31.8 \%$ males, $68.2 \%$ females, mean age $=36.46$ years, $\mathrm{SD}=15.62$ years) who were recruited from a general community in the north-west of England. Within the sample, $60.7 \%$ reported being Christian, $14.4 \%$ reported being Muslim, $3.4 \%$ Buddhist, $1.0 \%$ Hindu, $0.3 \%$ Sikh, $12.7 \%$ reported no religion, and $7.2 \%$ reported other religions. Self-reported ethnic group membership was as follows: $80.8 \%$ white, $1.0 \%$ mixed, $8.2 \%$ Asian, 6.5\% Asian British, 1.0\% black, 1.0\% black British and $1.4 \%$ of other ethnic origins. No respondents included in the final analysis were in any way directly involved with the London attacks.

\section{Instruments}

Biographical details

A biographical form was constructed to solicit information about demographic characteristics including age, gender, ethnicity, religion and presence in or association with the London attacks.

\section{Open-ended response form}

Respondents were briefly asked to indicate their personal feelings, experiences, or emotions in relation to the 7 July 2005 London attacks. This was extracted using the following probe:

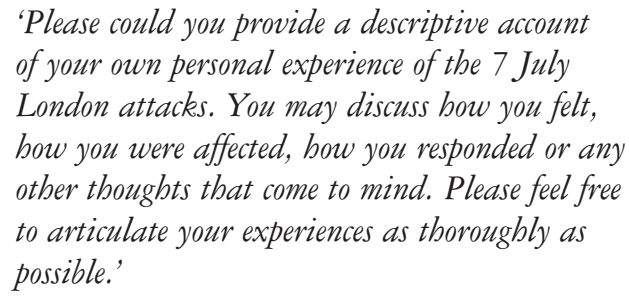

This format was preferred over more structured interview techniques, since it allowed a general overview of participants' responses to the attacks. This provided respondents more time and freedom to reply in their own way without being led by the interviewer on a sensitive and emotional subject. In addition, it made few assumptions about the nature of participant responses and allowed them the opportunity to discuss issues relevant within their context. An initial pilot study on 34 undergraduate students at a university in the northwest of England revealed a favourable and thorough response to this style of questioning, precluding the need for further questions.

\section{Procedure}

Questionnaires were distributed among a general community in north-west England using opportunity sampling. This sample was extracted by approaching community support groups, charities, businesses, religious faith groups, supermarkets, public libraries and universities within the northwest of England. Permission was sought in each case to distribute questionnaires to relevant parties. The nature of the study was fully explained and individuals in managerial positions either distributed questionnaires to individuals themselves or allowed individuals to pick up copies as they wished. Participants then decided to complete 
questionnaires on their own whim. Participants provided informed consent by completing questionnaires. In some cases email messages were sent to community groups explaining the nature of the study along with a copy of the questionnaire. Some respondents responded directly to the email. In an attempt to maximise representation, community groups ranging from religious faith organisations, cultural groups and gender-specific groups were also targeted. This allowed more direct control to be elicited over the nature of the sample, avoiding response bias although, ultimately, the final sample was determined by individuals themselves being willing to complete questionnaires. The sensitive nature of the study also warranted more care and control over the nature of the sample and the need to fully explain the study to all parties. This research was conducted according to the code of conduct set by the British Psychological Society (BPS). The questionnaire form was returned to the author either by personal collection or by post, while $1 \%$ of respondents used email. Questionnaires were distributed between November 2005 and March 2006.

\section{Analyses}

\section{Thematic analysis}

Qualitative content analysis was used to guide the analysis of the open-ended questionnaire responses. The analysis objective was to develop a profile of personal feelings, which characterised reactions towards the London attacks in respondents not directly affected. A coding scheme was developed following a thorough review of the questionnaires. Codes were developed on the basis of concordant units of information, sentences or paragraphs. This was based on an open-coding method without preconceived notions of participant's responses. This provided a more thorough reflection of the broader response to the London attacks and highlighted the heterogeneity of the effects of terrorism. Coding rules for negative and positive emotions were generated on the basis of the Differential Emotions Scale (DES) initially developed by Izard (1977), and concordance between the two authors. Coding rules for perceived risk were generated using the Lerner, Gonzales, Small and Fischoff (2003) scale, initially used on a nationally representative sample of Americans following the September 11 attacks on the United States. Subsequent codes were based on mutual agreement between the two authors. New codes were continually generated to reflect the response of all participants. The final scheme generated seven codes. For some codes, sub-categories were developed to enrich the analyses and ease interpretation. The two authors reviewed all questionnaires to ensure the final coding scheme reflected all responses.

To increase internal validity (Mays \& Pope, 2000; Miles \& Huberman, 1994), and prior to the development of the final coding scheme, a coding check on a random sample of $20 \%$ of questionnaires was conducted by the second author. The second author read the accounts thoroughly and developed a separate list of codes. Kappa coefficients revealed an initial agreement level of .69, close to the proposed level of .70 (Bakeman \& Gottman, 1986). A re-review of all codes was conducted by both authors and agreement reached on the final set of codes. A final coding check was then conducted on $10 \%$ of the whole questionnaire sample. Kappa coefficients indicated a strong agreement level of .83 .

\section{Linguistic analysis}

Each response was also analysed using a linguistic textual programme called Linguistic Inquiry and Word Count (LIWC: Pennebaker et al, 2001). The purpose of this analysis was to supplement the above by providing a more comprehensive analysis of the data. This programme provides a frequency count of various words and categories and is a fast, reliable way of assessing various personality factors (Pennebaker et al, 1999). The frequency counts are converted into percentages by the programme and are then placed into over 70 different dimensions. These dimensions can best be expressed by the use of four main categories: standard language properties (eg. pronouns, articles), psychological processes (eg. positive and negative emotion words), relativity-related words (eg. verbs, time) and traditional content (eg. home, family, sex). Various psychological constructs such as selfesteem (Bosson et al, 2000), positivity (Cohn et al, 2004), depression (Rude et al, 2004), and honesty (Slatcher et al, 2007) can then be assessed by analysing various aspects of each category.

Following Cohn et al (2004), we decided to structure subsequent analyses on the following five categories. 
A narrative account of the wider impact of the 7 July 2005 London bomb attacks

\section{Emotional positivity/negativity}

Positive emotions in the aftermath of trauma can help individuals cope with the situation and protect mental health. Therefore participants' use of positive emotion words compared with negative emotion words were analysed.

\section{Psychological distancing}

After trauma, many individuals may attempt to distance themselves from the situation. This is shown by the use of fewer words in the present tense compared with other tenses (Pennebaker \& King, 1999).

\section{Social awareness}

During stressful situations, individuals often become more concerned with their family and social world. Therefore, we assessed social awareness by comparing the use of first person singular pronouns (eg. 'I') with other pronouns (eg. 'they', 'he/she').

\section{Cognitive processing}

Individuals who use causal words (eg. because) have been shown to recover more quickly from trauma than other individuals (Pennebaker $e t$ al, 2003). Therefore, causal words were compared across groups to assess any differences in predicted recovery time.

\section{Religion}

As religion played a large role in the London bombings, we also assessed the use of religious words (eg. 'God', 'prayer') and how it was perceived by various religious groups. Although this category was not analysed in Cohn and colleagues' (2004) study, we felt that this category was particularly relevant to the
London bombings considering the large Muslim population in the $\mathrm{UK}$.

\section{Results}

Thematic analysis

There were five main conceptual categories derived from the analysis, with sub-categories emerging from the data within all of them. Table 1 shows a summary of the results. Categories included negative emotions, positive emotions, apathy, expectancy attributions and religiosity. Brief quotations from respondents are provided below for illustrative purposes.

\section{Negative emotional responses}

Participant descriptions of negative emotional responses $(n=268,79 \%)$ comprised of six main subcategories: feelings towards victims or those directly affected; concern for others; feelings about nature of attack/attackers; perceived risk; concern regarding response to attacks and feelings towards government.

\section{Feelings towards victims or those directly affected} Respondents reported a great deal of distress and sorrow for those directly involved in the attacks (18\%). The pain and suffering endured by those affected was equally felt by those not present at the scene. As one respondent put it:

\section{'I became deeply saddened for all the people injured and killed and their families, and I cried as I carried on watching.' (20-year-old white Christian female)}

\section{Concern for others}

Participants described feeling anxious and worried once they realised a friend or loved one could be caught up in the attacks (16\%). Many sought

Table 1: Summary of results

\begin{tabular}{llll} 
Negative emotions (79\%) & Positive emotions (10\%) & $\begin{array}{c}\text { Apathy (6\%) } \\
\text { Expectancy attributions } \\
\text { (29\%) }\end{array}$ & Religiosity (12\%) \\
\hline - Toward victims (18\%) & - Thankfulness/relief (6\%) & - Shock (23\%) & - Prayers (1\%) \\
- Concern for others (16\%) & - Pride (1\%) & - Inevitability (6\%) & - Incomprehension (3\%) \\
- Toward attackers (26\%) & & - Condemnation (6\%) \\
- Perceived risk (12\%) & & - Comfort (2\%) \\
- Regarding response (6\%) & & \\
- Toward govenment (2\%) & &
\end{tabular}


A narrative account of the wider impact of the 7 July 2005 London bomb attacks

to obtain immediate contact. As one participant reported:

'When I realised the bombs were on the underground I got scared because my sister lives in London and takes the underground to work. I frantically looked for a phone and called my family for any news.' (24-year-old white Christian female)

Feelings about nature of attack/attacker As typically expected following any terrorist atrocity, a great deal of negative sentiment was directed towards the perpetrators and the damage caused (26\%). Many reported feeling disgusted at the way the attacks were perpetrated. One participant said:

'Upon watching the news I was horrified and upset when I saw pictures of the attack, the injuries to people and the disruption it had caused London centre. It infuriates me to think people can do things like this to innocent people just to make a point!' (24-year-old female of mixed origin, no religion)

\section{Perceived risk}

Heightened perceived risk is a common response in the immediate aftermath of terrorist atrocity. For many people indirectly exposed, as in the present study, this sense of threat appears salient in the belief that another terrorist attack could be imminent (12\%). As one participant said:

\section{'I was affected by being apprehensive about going into Manchester City Centre the following weekend, because I thought something similar might happen there because it is a major city (just paranoia I guess).' (40-year-old female Asian British Muslim)}

\section{Concern regarding response to attacks} Several participants described feeling negative emotions as to how the attack was received $(6 \%)$. Some felt anger that retaliatory action was being taken, as conveyed by one participant:

'Over the next few days I saw how some people all over the country were attacking mosques and blaming the Muslim faith for what happened it made me angry that people would just cause. more burt when it wouldn't change anything.' (18-year-old white Christian female)

\section{Feelings towards government}

Few participants felt that more should have been done on the part of the government to stop such attacks $(2 \%)$. One participant said:

'I felt angry with the government for letting things go this far.' (19-year-old white female Christian)

\section{Positive emotional responses}

The second core category described participant descriptions of positive emotions experienced $(n=34,10 \%)$, which comprised of two main subcategories: thankfulness/relief and pride.

\section{Thankfulness and relief}

Respondents mainly expressed thanks and relief for their own safety and that of loved ones, which helped ease many of their feelings (6\%). As one respondent reported:

'I felt very lucky that I and none of my family or friends were involved in the incident.' (23-yearold white Christian female)

\section{Pride}

Few participants described feeling proud about the way the attack was handled and how people responded (1\%), as conveyed by one respondent:

'I felt proud of my country and its citizens in the way they all offered support and assistance regardless of race, religion and gender.' (31-yearold white Christian female)

\section{Apathy}

Several participants $(\mathrm{n}=19,6 \%)$ described feeling little or no emotion towards the London attacks. Participants reported that due to the distance from London they felt disassociated and could not relate to events that day. As one participant expressed:

\section{'Maybe it was because I live far away from London, but I felt quite removed from the situation.' (28-year-old white Christian female)}

\section{Expectancy attributions}

Many respondents described the extent to which they anticipated or did not anticipate the London attacks ( $\mathrm{n}=99,29 \%)$. Participants spoke of disbelief or inevitability that such attacks took place, which comprised the two main subcategories. 
A narrative account of the wider impact of the 7 July 2005 London bomb attacks

\section{Shock and disbelief at attacks}

For many participants, the initial shock arose from the knowledge that Britain had been attacked (23\%), which made terrorism seem more real and Britain less immune from such atrocities. One participant described:

'...shock that attacks such as this could be possible on mainland Britain. It made me aware that incidents like this did not just happen abroad.' (41-year-old white Christian male)

Inevitability about attacks

Certain participants spoke of the London attacks coming as no real surprise, and perhaps expected due to the warning signals that the public were previously alerted to regarding the vulnerability of London to terrorism (6\%). One participant conveyed:

'I was not shocked when London was bombed because I believe most people were expecting it to bappen at some stage.' (47-year-old white Christian male)

\section{Religiosity}

Participant descriptions of religion $(n=40,12 \%)$ comprised of four main subcategories: prayers for those affected; religious incomprehension; religious condemnation; comfort and assurance in faith.

\section{Prayers for those affected}

Several participants talked about religion as a way of connecting with those directly affected (1\%). Participants prayed that the families in particular would find a way to cope. One participant reported:

'As a Christian, I prayed for the situation, that families would find comfort in those times.' (20-year-old white Christian female)

\section{Religious incomprehension}

Many participants described finding it difficult to comprehend how the perpetrators could justify their actions from a religious perspective $(3 \%)$, as expressed by one respondent:

'I could not (and still cannot) understand how anyone who professes a faith in a just and good God could believe that He/She (ie. their God) could ever want them to murder people like this.' (62-year-old white Christian female)

\section{Religious condemnation}

Many people spoke of the perpetrators' actions as being completely against their own beliefs and what their own religion had taught them $(6 \%)$. They completely condemned such actions and believed that they could in no way be justified religiously. As one participant said:

'The religion of Islam is a peaceful religion; in no way does it condone the killing of innocent people. These bombers also committed a very sinful act of not just killing others but also committing suicide which is condemned and it is mentioned in Quran, that those who oppress others and kill innocent people and commit suicide will not be forgiven by God.' (43-year-old Muslim male)

\section{Comfort and assurance in faith}

Participants described solace in their faith and found that their beliefs helped them cope during a difficult period (2\%). They felt that God was protecting them and their loved ones. One participant reported:

'I felt assured that God had protected the people I know who worked in London because they are mostly Christians. I believe He protects us with His angels.' (20-year-old white Christian female).

\section{Linguistic analyses}

A textual analysis was conducted using LIWC. Various analyses as described earlier were conducted using SPSS version 15. Gender and ethnicity differences were assessed in each analysis. To make analyses meaningful, we only analysed differences between the two largest ethnic groups (white and Asian/Asian British). Religion differences were not analysed as $96 \%$ of Christians reported white ethnicity and $91 \%$ of Muslims reported Asian ethnicity. This resulted in a sample size of 279 participants (95\% of the overall sample).

\section{Emotional positivity/negativity}

A mixed analysis of variance (ANOVA) revealed that participants used significantly more negative emotion words $(\mathrm{M}=9.78, \mathrm{SD}=12.60)$ than positive emotion words $(\mathrm{M}=2.47, \mathrm{SD}=2.99)$, $(\mathrm{F}$ $(1,275)=38.96, \mathrm{p}<.001)$. However, there was no significant interaction between word use and ethnicity $(\mathrm{F}(1,275)=.02, \mathrm{p}=.90)$, or gender, $(\mathrm{F}$ $(1,275)=.03, \mathrm{p}=.86)$. 
A narrative account of the wider impact of the 7 July 2005 London bomb attacks

\section{Psychological distancing}

To assess psychological distancing, participants' use of present, past, and future tense words were analysed. A mixed ANOVA revealed a significant difference overall $(\mathrm{F}(1.34,369.72)=89.98$, $\mathrm{p}<.001)$. Table 2, below, shows the mean and standard deviations. Pairwise comparisons (all significant at the $\mathrm{p}<.001$ level) revealed that overall, participants used past tense words most frequently, followed by present tense words. Future tense words were rare compared to other words.

The analysis also revealed a significant interaction between word use and ethnicity $(\mathrm{F}$ $(1.34,369.72)=7.34, \mathrm{p}<.01)$, though not for gender $(\mathrm{F}(1.34,369.72)=.26, \mathrm{p}=.68)$. Pairwise comparisons (all significant at the $\mathrm{p}<.001$ level) revealed that the pattern above held for white participants. However, although Asian participants used significantly lower amounts of future tense than other words $(\mathrm{p}<.001)$, they used equal amounts of past and present tense words $(\mathrm{t}$ $(42)=.40, \mathrm{p}=.69)$.

\section{Social awareness}

To determine social awareness, we compared the use of first singular pronouns (eg. 'I') with other pronouns (eg. 'they', 'he'). A mixed ANOVA revealed that participants used significantly more 'other' pronouns $(\mathrm{M}=5.13, \mathrm{SD}=4.29)$ than 'self pronouns, $(\mathrm{M}=7.88, \mathrm{SD}=5.12), \mathrm{F}(1,275)=32.26$, $\mathrm{p}<.001)$. There was no significant interaction between word use and ethnicity $(\mathrm{F}(1,275)=2.03$, $\mathrm{p}=.16)$ or gender $(\mathrm{F}(1,275)=.47, \mathrm{p}=.49)$.

\section{Cognitive processing}

A $2 \times 2$ ANOVA revealed that was no significant main effect of gender $(\mathrm{F}(1,275)=.75, \mathrm{p}=.39)$ or ethnicity $(\mathrm{F}(1,275)=.25, \mathrm{p}=.62)$ on causation word use. There was also no significant interaction between these variables $(\mathrm{F}(1,275)=.15, \mathrm{p}=.70)$.

\section{Religion}

A $2 \times 2$ ANOVA was conducted to assess differences in words related to religion. The analysis revealed no significant effect of gender on word use $(\mathrm{F}(1,274)=.01, \mathrm{p}=.93)$. However, a trend was revealed for ethnicity $(\mathrm{F}(1,274)=3.06$, $\mathrm{p}=.08)$, namely that Asian participants $(\mathrm{M}=.91$, $\mathrm{SD}=1.92)$ used nearly twice as many religious words than white participants $(\mathrm{M}=.50, \mathrm{SD}=1.16)$. The analysis also revealed a non-significant interaction between gender and ethnicity ( $\mathrm{F}$ $(1,274)=.01, \mathrm{p}=.94)$.

\section{Discussion}

The results of the study highlighted a complex array of responses to terrorism. The effects of the London attacks in the present sample appear to support a relatively restrained effect on wider society. Although responses were predominantly depicted by negative emotions, this was partly expected given the nature of terrorism. However, there appeared to be no signs of prolonged trauma or severe anxiety in the wake of the attacks, despite the extreme and bloody nature of terrorism. Most respondents described the callous nature of the attacks, and struggled to comprehend the atrocity inflicted. Some felt sorrow and anxiety for those directly involved and in the fear that loved ones may be amid the disaster. Although none of the individuals in the study had any connection to the victims of the bombings many still identified with the direct victims of the attack, and showed greater direct concern for others than for self. This is consistent with the findings of a study on linguistic indicators of psychological change following 9/11 (Cohn et al, 2004). Affiliation with others during times of emotional stress can serve as a protective mechanism (Cohen \& Wills, 1985), which may help explain the robust ability of white and Asian respondents to recover equally as fast, as measured by their level of cognitive processing.

\begin{tabular}{|c|c|c|c|c|c|c|c|c|c|c|}
\hline \multirow[b]{3}{*}{$\begin{array}{l}\text { Word } \\
\text { Tense }\end{array}$} & \multicolumn{4}{|c|}{ Ethnicity } & \multicolumn{4}{|c|}{ Gender } & \multicolumn{2}{|c|}{ Overall } \\
\hline & \multicolumn{2}{|l|}{ White } & \multicolumn{2}{|l|}{ Asian } & \multicolumn{2}{|l|}{ Male } & \multicolumn{2}{|l|}{ Female } & \multirow[b]{2}{*}{$M$} & \multirow[b]{2}{*}{ SD } \\
\hline & $M$ & SD & $\mathbf{M}$ & SD & $M$ & SD & $M$ & SD & & \\
\hline Past & 8.78 & 6.31 & 7.66 & 4.82 & 8.28 & 7.65 & 8.76 & 5.26 & 8.61 & 6.11 \\
\hline Present & 3.85 & 3.83 & 7.12 & 5.28 & 418 & 4.19 & 4.43 & 4.29 & 4.50 & 4.25 \\
\hline Future & .82 & 1.46 & .57 & 1.06 & .86 & 1.68 & .74 & 1.27 & .78 & 1.41 \\
\hline
\end{tabular}


Given this, the results did not support any severe psychological impact for self, in contrast to research carried out following the Oklahoma bombing in 1995 (Pfefferbaum, 2003). The media coverage following the attack was particularly intense within Oklahoma, resulting in psychological problems among some adults and children as a consequence of long exposure to media coverage. Although these individuals had not been near the scene of the attack or directly connected with any of the victims of the attacks, they still reported anxiety problems, depression and difficulties in sleeping. The study, nevertheless, was conducted in the city where the attacks occurred, unlike the present study. Despite this, the present study did not account for extent of media coverage, which may have been a strong predictor of extent to which individuals experienced negative emotions. Future research may also look to explore how media coverage impacted on those living within London, but not directly involved in the attacks.

The results of the study were compelling in understanding how emotional responses impinge on perceived risk. Perceived risk was a common theme linked to negative emotions. Some respondents reported uncertainty in the knowledge that future attacks might occur indiscriminately at any place or time. The results of the study appeared to support the theory that terrorism is a form of 'psychological warfare' (Friedland \& Merari, 1985), the effects of which go beyond the immediate victims. However, this sense of anxiety or worry, as supported by the extent to which negative emotional words were used, appeared to be mediated by the use of psychological distancing strategies and a displacement of concern for self onto concern for others, precluding signs of severe trauma. The results of the study were also significantly lower than the $55 \%$ of individuals in London who reported a sense of personal risk following the 7 July attacks, and $58 \%$ who reported concern for family and friends (Rubin $e t a l$, 2005). More significantly, the results in this study were appreciably lower than the $41 \%$ of nursing students who felt that terrorism was 'somewhat likely' to occur nine months after September 11 (Young \& Persell, 2004). Despite the probability of dying in a terrorist attack being much lower than death in a car accident, attributions of this nature are surprisingly common. Tversky and Kahneman (1973) label these attributions as 'heuristics'. One of these heuristics is availability. This can erroneously lead us to suppose that risky events are much more likely to take place than they are if we can willingly call examples to mind. Given that respondents were probed into thinking back to the London attacks, this sense of risk may have been the result of an availability bias. The availability of such images has the potential to distort our perceptions of the actual risk to which we are exposed. In this light, the power of terrorism to overawe should not be taken for granted. Accurate risk assessment and communication should be a fundamental component in tackling the wider impact of terrorism on societies.

Numerous respondents reported slight concern regarding the response to the London attacks and government policy in general. Particularly illuminating was the sense of retaliatory action against certain sectors of the community, and concerns related to secondary victimisation. Previous studies have shown that violence, or the threat of violence, outside the conventions of what is normal in any society

$$
\begin{aligned}
& \text { 'works to bind communities together with a sense } \\
& \text { of common purpose and common outrage. Combined } \\
& \text { with the perception that there is a shared enemy } \\
& \text { out there, terrorist attacks bolster individuals' ties } \\
& \text { to their local community, deepening their sense } \\
& \text { of belonging and their identification with others } \\
& \text { living in the area' (Silke, 2003: 27). }
\end{aligned}
$$

It was shown in this study that respondents felt a sense of concern for their social world, in particular direct victims, family and loved ones. This sense of social orientation is an important quality in helping harness a unified community response to terrorism, which

$$
\begin{aligned}
& \text { '... can actually end up working to improve the } \\
& \text { ability of most people to cope and respond positively } \\
& \text { to it' (Silke, 2003: 28). }
\end{aligned}
$$

Reports of positive emotions were less common. Although previous studies have illustrated how feelings of love and trust can serve to reduce panic and apprehension, only a few respondents reported a sense of comfort in the knowledge that loved ones were safe. A recent analysis of the effects of emotions and coping responses on estimates of risk revealed that positive emotions had no significant influence on perceived risk in relation to the London attacks (Bux \& Coyne, in press). Positive feelings may not have seemed directly relevant for respondents in relation to the terrorist attacks, however the benefits of positive emotions may be more explicit for those in the direct vicinity of 
the attack, particularly in witnessing how people respond and continue with their lives. While the ubiquitous nature of negative emotions over and above positive emotions may generally be taken as one indicator of trauma (Rimé et al, 1998), the nature and expression of negative emotions within the present study appeared to support a broader sense of negative sentiment, as opposed to any specific symptoms in relation to self.

Several participants reported feelings of apathy. The geographical proximity and lack of direct connection with the bombings precluded any sense of emotions for some individuals. However, this sense of psychological distancing was more apparent among white respondents than Asian respondents. This can possibly be explained by the increasing attention and focus on Asians as an ethnic group following the attacks, limiting their ability to use such strategies, and perhaps feeling a more direct affiliation with the attacks overall than white respondents. Importantly, however, the ability to distance themselves from the attacks among white respondents did not predict and increase their ability to recover from the attacks more quickly than Asian respondents. This indicates that although Asian respondents may not have used psychological distancing as often, the effects of the attacks were no more acute in their context. In this domain, some respondents described a sense of desensitisation and inevitability that London will be attacked. Given that terrorism has of late attracted huge media interest, it appears that for some there is almost an acceptance that terrorism will occur. Alternatively, the nature and scale of terrorism may have hardened attitudes among the community. For example, over a sevenmonth period, Rubin and colleagues (2007) found that a decrease in travel following the London bombings, although prevalent, continued at a lower intensity. While clearly many continue to suffer the effects of terrorism, particularly victims directly affected (eg. Curran et al, 1990), many others exhibit signs of psychological resilience (Curran et al, 1990), which may be a crucial defence in how certain people are able to react during times of adversity.

Religiosity was another common quality of respondent's feelings regarding the London attacks. Some participants felt a sense of comfort and assurance in faith partially consistent with prior research conducted on Asian, black and Latino New York City residents following the 9/11 attacks (Constantine et al, 2005), which showed a range of prevalent emotions, along with the effectiveness of coping responses such as religion and spirituality. Religion helped provide a sense of control (Meisenhelder, 2002) for many people, indicating its effectiveness as a coping mechanism. Some respondents in this study, in particular Muslims, expressed overt religious condemnation, wishing to disassociate themselves from such activity. Respondents reported that terrorism could not be religiously justified or condoned under any circumstances. Recent initiatives, such as the Not in Our Name campaign launched by British Muslims following the London and Glasgow bomb plots, may be crucial avenues for undermining tacit and passive support for terrorism. More specifically, Asian respondents reported more religious references than white respondents, a finding that can be explained by the direct connection between religion and the origin of the perpetrators in popular and political discourse following the London attacks. However, as these findings show, religious references are expressed in many disparate domains and religious faith may also be an important protective mechanism.

Overall, the results of this study demonstrated a ubiquitous nature of negative emotions with regard to the London attacks. However, respondents exhibited this more with respect to references to others than for self, serving as an important protective barrier and mediating the sense of widespread fear and anxiety. This sense of generalised anxiety, although at times may spill out into increased perceptions of risk, generally allows individuals to orient themselves more acutely to the social world, and may be crucial in harnessing unified community-based responses. Some respondents, in particular white respondents, used more psychological distancing strategies than Asian respondents, although this did not impact on the ability to recover. Others used religion as a coping strategy, and references to religion were more apparent among Asian respondents than white respondents. In summary, although terrorism has a vicarious quality that can potentially traumatise and shake entire countries, the results of this study appear to show that societies are more resilient in dealing with the effects of terrorism, and its effects are not as profound or widespread as might be expected.

\section{Limitations}

Data in the present study was collected over a period of three months, without the control of 
time-sampling bias. The time lapse may have impinged on respondents who completed the questionnaires at a later date. The generalisability of qualitative results to other contexts is questionable considering that responses were limited to one community distant from the London terrorist attacks. Comparative studies on the wider effects of terrorism would be highly valued. Proximity to the London attacks may have influenced the nature of response, and future research should look to examine geographical proximity as a function of perceived risk of terrorism. A more nationally representative sample, in accordance with previous work on the effects of terrorism (Lerner et al, 2003), may allow for greater generalisability of results and provide a more robust indication of the broader effects of terrorism. The sample in the present study was, however, broadly representative of the community in which it was extracted, as evidenced by the diverse representation of ethnicities and religious faiths. Level of media exposure was another variable not controlled in the present study and this may have influenced how respondents perceived the level of threat and personal risk. Future research may look to utilise a longitudinal sample to discern whether media attention to terrorism in the weeks and months following an attack reinstates emotions and feelings enacted at the time of the attacks. Understanding how this affects perceptions of threat may provide broader understanding of how risk estimates are constituted.

\section{Summary}

Terrorism by its very nature creates ripples of worry and anxiety. It was the aim of this study to understand the psychological impact of the 7 July 2005 London attacks on a community not directly affected by terrorism. The study showed that responses to terrorism are complex and heterogeneous. It also illustrated that while terrorism has the ability to elicit widespread negative emotionality, references to others, the use of psychological distancing and religious faith can be used as strategies to mediate the effects that terrorism may exert. While a sense of social orientation may limit generalised risk, it may also be a crucial mechanism in helping harness unified community responses. While this study shows that terrorism may not exert as damaging psychological effects as may be believed, it can have much wider and more profound effects on particular communities. More importantly, by understanding the words and narratives of broader communities, this study shows how the more subtle effects and consequences of terrorism can be discerned.

\section{Implications for policy-making/practice}

- We found evidence that many individuals not directly involved in a terrorist attack are still psychologically affected. Therefore, communities not directly involved in terrorist attacks should create policies to help community members, even though such individuals were not directly involved in the attack.

- Such policy should focus on a social orientation that connects community members and provides opportunity for service. Having a social orientation after a terrorist attack may limit generalised risk and bring those in the community together in a time of crisis.

- Such policy should also be cognisant of religious differences in the community. Initiatives similar to the Not in Our Name campaign (discussed in the article) may be useful in communities indirectly exposed to terrorist attacks.

Address for correspondence

Sarah M Coyne

Brigham Young University

School of Family Life

JFSB 2087

Provo, UT 84602

USA

Email: smcoyne@byu.edu

\section{References}

Apolone G, Mosconi P \& La Vecchia C (2002) Posttraumatic stress disorder. New England Journal of Medicine 346 1495-1498.

Bakeman R \& Gottmann JM (1986) Observing Interactions: An introduction to sequential analysis. Cambridge: Cambridge University Press.

Bosson JK, Swann WB \& Pennebaker JW (2000) Stalking the perfect measure of self-esteem: The blind men and the elephant revisited? Journal of Personality and Social Psychology 79 631-643.

Bux S \& Coyne SM (In press) The effects of terrorism: The aftermath of the London terror attacks. Journal of Applied Social Psychology (available from the authors).

Cohen S \& Wills TA (1985) Stress, social support, and the buffering hypothesis. Psychological Bulletin 98 310-357. 
A narrative account of the wider impact of the 7 July 2005 London bomb attacks

Cohn MA, Mehl MR \& Pennebaker JW (2004) Linguistic markers of psychological change surrounding September 11, 2001. Psychological Science 15 687-693.

Constantine MG, Alleyne VL, Caldwell LD, McRae MB \& Suzuki LA (2005) Coping responses of Asian, black, and Latino/Latina New York city residents following the September 11, 2001 terrorist attacks against the United States. Cultural Diversity and Ethnic Minority Psychology 11 293-308.

Curran PS, Bell P, Murray A, Loughrey G, Roddy R \& Rocke LG (1990) Psychological consequences of the Enniskillen bombing. British Journal of Psychiatry 156 479-482.

Fredrickson BL (1995) Socioemotional behaviour at the end of college life. Journal of Personal and Social Relationships 12 261-276.

Fredrickson BL \& Carstensen LL (1990) Choosing social partners: How old age and anticipated endings make people more selective. Psychology and Aging 5 335-347.

Friedland N \& Merari A (1985) A psychological impact of terrorism: A double-edged sword. Political Psychology 6 591-604.

Galea S, Ahern J, Resnick H, Kilpatrick D, Bucuvalas M, Gold J \& Vlahov D (2002) Psychological sequelae of the September 11th Terrorist Attacks in New York City. New England Journal of Medicine 346 982-987.

Gallup News Service (2001) Attack on America: key trends and indicators. In: A Graphic Summary of Public Opinion Following September 11th. Available from: http:// www.gallup.com/poll/releases/pr01092c.asp (accessed 20 January 2006).

Gurwitch RH, Sitterle KA, Young BH \& Pfefferbaum B (2002) The aftermath of terrorism. In: AM La Greca, WK Silverman, EM Vernberg \& MC Roberts (Eds) Helping Children Cope with Disasters and Terrorism (pp327-357). Washington, DC: American Psychological Association.

Healy AF, Hoffman JM, Beer FA \& Bourne LE Jr (2002) Terrorists and democrats: Individual reactions to international attacks. Political Psychology 23 439-467.

Hoffman B (1998) Inside Terrorism. New York: Columbia University Press.

Izard CE (1977) Human Emotions. New York: Plenum Press.

Kirkup J (2005) Muslims live in fear as revenge crimes escalate. The Scotsman, Thursday 14 July.

Lerner JS, Gonzalez RM, Small DA \& Fischoff B (2003) Effects of fear and anger on perceived risks of terrorism: a national field experiment. Psychological Science 14 144-150.

Mays N \& Pope C (2000) Qualitative research in health care. Assessing quality in qualitative research. British Medical Journal 320 50-52.

Meisenhelder JB (2002) Terrorism, posttraumatic stress, and religious coping. Issues in Mental Health Nursing 28 771-782.
Miles MB \& Huberman AM (1994) Qualitative Data Analysis: An expanded sourcebook. Thousand Oaks, CA: Sage.

Mueller J (2005) Six rather unusual propositions about terrorism. Terrorism and Political Violence 17487.

Pennebaker JW, Francis ME \& Booth RJ (2001) Linguistic Inquiry and Word Count: LIWC 2001. Mahwah NJ: Erlbaum Publishers.

Pennebaker JW \& King LA (1999) Linguistic styles: language use as an individual difference. Journal of Personality and Social Psychology 77 1296-1312.

Pennebaker JW, Mehl MR \& Neiderhoffer KG (2003) Psychological aspects of natural language use: our words, our selves. Annual Review of Psychology 54 547-577.

Pfefferbaum B (2003) Victims of terrorism and the media. In: A Silke (Ed) Terrorists, Victims and Society: Psychological perspectives on terrorism and its consequences (pp175-189). Chichester: Wiley.

Press Association (2005) Sales slump in London after bombs. The Guardian, Tuesday 16 August.

Rimé B, Finkenauer C, Luminet O, Zech E \& Philippot P (1998) Social sharing of emotion: New evidence and new questions. In: W Stroebe \& M Hewstone (Eds) European Review of Social Psychology (Volume 9, pp145-189).

Chichester: Wiley.

Rubin GJ, Brewin CR, Greenberg N, Simpson J \& Wessely S (2005) Psychological and behavioural reactions to the bombings in London on July 7 2005: a cross sectional survey of a representative sample of Londoners. British Medical Journal 331 606-611.

Rubin GJ, Brewin CR, Greenberg N, Hughes JH, Simpson J \& Wessely S (2007) Enduring consequences of terrorism: 7-month follow-up survey of reactions to the bombings in London on 7th July 2005. British Journal of Psychiatry 190 350-356.

Rude SS, Gortner EM \& Pennebaker JW (2004) Language use of depressed and depression-vulnerable college students. Cognition and Emotion 18 1121-1133.

Saad L (2001a) Americans anxious, but holding their heads high: have increased confidence in government leaders, the economy. Gallup News Service. Available from: http:// www.gallup.com/poll/releases/pr011001.asp (accessed 20 January 2006).

Saad L (2001b) Personal impact on Americans' lives: women express much more fear of terrorism than do men. Gallup News Service. Available from: http://www.gallup. com/poll/releases/pr010914e.asp (accessed 20 January 2006).

Schuster M, Bradley D, Stein M, Jaycox LH, Collins RL, Marshall GN, Elliot MN, Zhou AJ, Kanouse DE, Morrison JL \& Berry SH (2001) A national survey of stress reactions after the September 11, 2001 terrorist attacks. New England Journal of Medicine 345 1507-1512. 
A narrative account of the wider impact of the 7 July 2005 London bomb attacks

Silke A (2003) The psychological cost of terrorism. Forensic Update 72 23-29.

Slatcher RB, Chung CK, Pennebaker JW \& Stone LD (2007) Winning words: individual differences in linguistic style among U.S. presidential and vice presidential candidates. Journal of Research in Personality 41 63-75.

Smith L (2005) Plea for cut rates in wake of bombings. The Guardian, Saturday 20 August.

Somer E, Ruvio A, Soref E \& Sever I (2005) Terrorism, distress and coping: high versus low impact regions and direct versus indirect action exposure. Anxiety, Stress, and Coping 18 165-182.
Sprang G (1999) Post-disaster stress following the Oklahoma City bombing: an examination of the three community groups. The Journal of Interpersonal Violence 14 161-175.

Tversky A \& Kahneman D (1973) Availability: a heuristic for judging frequency and probability. Cognitive Psychology $5207-232$.

Young CF \& Persell DJ (2004) Biological, chemical, and nuclear terrorism readiness: major concerns and preparedness of future nurses. Disaster Management and Response 2 109-114.

\section{Advances in Dual Diagnosis

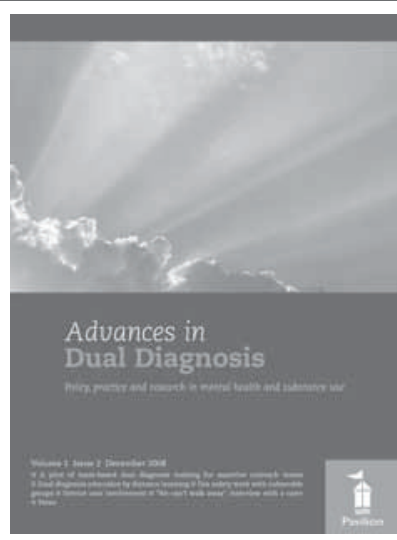

\section{Save $\mathbf{2 0} \%$ on two-year subscriptions}

- INSTITUTIONAL LARGE - print and online (500+ online users)

- INSTITUTIONAL MEDIUM - print and online (50 to 499 online users)

- INSTITUTIONAL SMALL - print and online (2 to 49 online users)

- INSTITUTIONAL - print and online (I online user)

- INDIVIDUAL - print and online

ISSN: 1757-8043 treatment in the UK.

The Journal will provide a forum for the dissemination of:

$\boldsymbol{\square}$ international updates $\mathbf{D}$ policy updates and their implications for practice

\section{ALL ISSUES OF THE JOURNAL}

Online access now authenticated by IP address, Athens and Shibboleth

The dual diagnosis of people with mental health problems who also use drugs or alcohol is an area of significant concern for health services today. Despite the growing number of people receiving dual diagnosis, to date there has been a lack of joined-up thinking across mental health and substance use services about how to treat

best practice and innovative services current research $\mathbf{\square}$ user and carer perspectives

\section{ALL SUBSCRIPTIONS INCLUDE FREE ONLINE ACCESS TO}


Reproduced with permission of the copyright owner. Further reproduction prohibited without permission. 